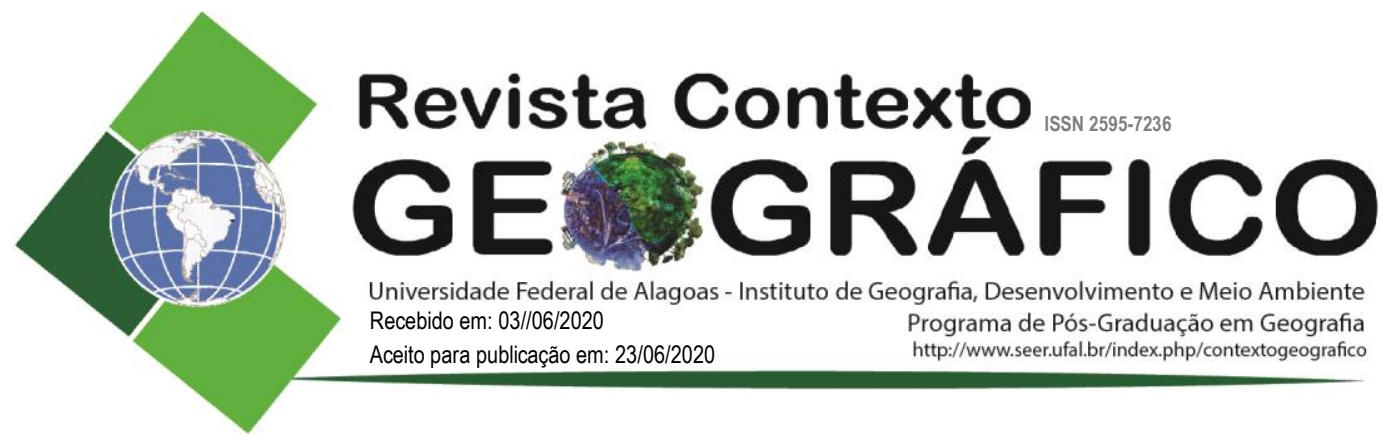

\title{
OS CICLOS PRODUTIVOS DO CLUSTER NAVAL DE NITERÓI E SÃO GONÇALO: POLÍTICAS ESTATAIS E DESAFIOS PARA UMA PRODUÇÃO A LONGO PRAZO
}

\author{
Maíra Neves de Azevedo \\ Geógrafa com Mestrado em Geografia pelo PPGG-UFRJ, bolsista FAPERJ, RJ, Brasil \\ maira.neves.azevedo@gmail.com
}

\begin{abstract}
RESUMO - No contexto de uma produção global, o presente artigo tem como objetivo analisar o papel do cluster naval de Niterói e São Gonçalo no circuito espacial de produção de embarcações. A escolha dos municípios ocorre pela importância histórica do ramo naval na região da Baía de Guanabara. A metodologia consistiu em revisão bibliográfica; consulta a estatísticas; elaboração de mapas; e entrevistas com trabalhadores e instituições do setor. Os resultados apontam que: a localização em aglomerados é comum no ramo naval; o Estado, por meio de suas normas, é o principal impulsionador da produção de embarcações no Brasil; desde os anos 2000, a produção de navios serve como suporte para a produção de petróleo offshore; existe dificuldade de manutenção do ramo a longo prazo, pois os estímulos estatais pecam no investimento em inovação; existe uma tendência atual de especialização do ramo no reparo de embarcações. Por fim, o estudo aponta a necessidade de fortalecimento das relações horizontais entre as instituições para que a indústria naval seja um efetivo vetor para o desenvolvimento territorial dos municípios.
\end{abstract}

Palavras-chave: Indústria naval; Petróleo offshore; Circuito espacial de produção; Localização industrial.

\section{THE PRODUCTIVE CYCLES OF THE NITERÓI AND SÃO GONÇALO NAVAL CLUSTER: STATE POLICIES AND CHALLENGES FOR LONG- TERM PRODUCTION}

\begin{abstract}
In the context of a global production, this article aims to analyze the role of Niterói and São Gonçalo naval cluster in the spatial circuit of vessels production. The choice of the two municipalities is due to the historical importance of this industrial branch in the Guanabara Bay region. The methodology consisted of a bibliographic review; statistics review; map making; and interviews with industry workers and institutions. The results indicate that: the location in clusters is common in the naval branch; the State, through its rules, is the main driver of vessel production in Brazil; since the 2000s, ship production has served as a support for offshore oil production; there is difficulty in maintaining long-term production, as state incentives fail to invest in innovation; there is a current trend of specialization in the field of vessel repair. Finally, the study points out the need to strengthen horizontal relations between institutions, so that the shipping industry can become a vector for the territorial development of municipalities.
\end{abstract}

Keywords: Shipbuilding industry; Offshore oil; Spatial production circuit; Industrial location.

\section{INTRODUÇÃO}

O desenvolvimento econômico das sociedades está altamente correlacionado com a troca de mercadorias. Se em um primeiro momento essas trocas ocorreram pelo escambo e a curtas distâncias, com o aprimoramento técnico e com a construção de novos meios de transporte, 
essas populações conseguiram superar rios, lagos, e até oceanos, o que permitiu que a circulação de mercadorias atingisse praticamente todo o planeta (ARROYO, 2004). Ao longo dos últimos séculos, a diminuição das barreiras ao livre comércio e a organização produtiva em forma de rede alargaram e dinamizaram ainda mais as trocas comerciais.

Para acompanhar esse processo, navios cada vez mais velozes e com mais capacidade de armazenagem começaram a ser construídos (MONIÉ e VIDAL, 2006). Na seara de novas embarcações se destacam os porta-contêineres, os graneleiros, e os roll-on roll-off, capazes de carregar bens industrializados e commodities para diversas partes do mundo. Essa grande capacidade de armazenagem e de deslocamento acabaram garantindo destaque para o transporte marítimo, que chega a ser responsável por cerca de $90 \%$ do transporte internacional de cargas (MONIÉ, 2015).

A construção de navios é uma técnica conhecida há séculos, de tal modo, ela já sofreu inúmeras transformações para se adequar aos diversos períodos históricos. No atual estágio da globalização, em que vemos a ascensão da ciência e da informação, os grandes navios incorporam as tecnologias informacionais e propiciam maior agilidade nas trocas comerciais. Essas embarcações exigem técnicas arrojadas de construção, e, consequentemente, a presença de engenheiros qualificados, além de mão de obra abundante disponível. Desde a metade do século XX, países como Japão, Coreia do Sul e China conseguem articular esses fatores e fazem com que mais de $80 \%$ da produção mundial de embarcações seja proveniente da Ásia (SENTURK, 2011).

Como é essencial que os navios sejam produzidos próximos à corpos d'água, os estaleiros acabam se instalando em baías ou na foz de rios, que são áreas com águas mais calmas. Contudo, essas vantagens produtivas não dependem apenas de aspectos naturais, mas também de condições locais de ordem técnica - como a presença de infraestrutura - e organizacional, por meio de leis, relações trabalhistas etc. (SANTOS, 2008). Esse aspecto locacional bastante particular acaba favorecendo que a indústria naval se aglomere na proximidade de poucas cidades, como Xangai, Hiroshima, Hong Kong e Ulsan. Essa arquitetura locacional se repete em diversos locais, o que nos traz à hipótese de que alguns estaleiros se beneficiam das economias de aglomeração, como em clusters, que permitem maior facilidade no acesso aos fornecedores e geram um acúmulo de "saber-fazer", especialmente em um contexto de construção de embarcações maiores e dotadas de equipamentos mais específicos.

No Brasil, a forma de localização não é muito diferente. Por motivos geográficos e históricos, a indústria naval nacional encontra-se aglomerada, majoritariamente, no estado do Rio de Janeiro. Apesar da semelhança no tipo de disposição, nas últimas décadas, a construção de navios em nosso país passou a acompanhar uma dinâmica um pouco diferente do comércio mundial de longas distâncias. Com o avanço da exploração de petróleo offshore e por meio de incentivos governamentais, boa parte das embarcações construídas no Brasil voltaram-se para a prospecção, produção e transporte desse hidrocarboneto (EGLER e MATTOS, 2012).

Ao longo do século XXI, os números da produção naval brasileira não se comparam aos dos países asiáticos citados. Não obstante, essa simbiose entre a indústria naval e a petrolífera permitiu que se expandisse o número de embarcações construídas no Brasil entre 2000 e 2014. Para ilustrar essa mudança, no início desse período o setor empregava apenas 1,9 mil pessoas no Brasil e em 2012 esse valor já chegava a 62 mil (BARAT, CAMPOS NETO e PAULA, 2014). A chave para essa mudança estava, principalmente, na exigência de conteúdos locais para a exploração de petróleo na costa. Contudo, se por um período a dependência da indústria do petróleo gerou essa grande demanda, a partir de 2015, essa situação causou uma das maiores crises já vistas no ramo. O colapso institucional na Petrobras e a desvalorização do barril de petróleo deflagraram uma queda nos pedidos e, consequentemente, uma série de demissões (FIRJAN, 2016). 
Assim, apesar da indústria naval brasileira possuir uma configuração espacial semelhante à de outros países, por sua forma aglomerada, há desafios bastante específicos para a manutenção da produção. Em outras palavras, apesar do litoral ser extenso e de haver potencial para o uso de embarcações, o setor naval brasileiro apresenta dificuldades na manutenção de pedidos a longo prazo.

Para compreender as formas desse setor no território nacional, escolhemos como recorte os municípios de Niterói e São Gonçalo - que ocupam a porção leste da Baía de Guanabara-, berços da indústria naval brasileira, que abrigam uma das principais concentrações de estaleiros no país. A história da indústria naval brasileira se confunde com o histórico do ramo nesses municípios. A metodologia teve como base a revisão bibliográfica, a consulta de dados estatísticos do Ministério do Trabalho e Emprego e de instituições setoriais, a elaboração de mapas e a realização de entrevistas com trabalhadores e instituições do setor (abordamos trabalhadores de estaleiros, o presidente da Sociedade Brasileira de Engenharia Naval, o Assessor de Planejamento e Gestão Estratégica da Companhia de Desenvolvimento Industrial do Estado do Rio de Janeiro, e o Secretário de Desenvolvimento Econômico, Indústria Naval e Petróleo e Gás de Niterói). Deste modo, buscamos, ao longo do trabalho, compreender as especificidades da indústria naval brasileira, com base na análise de sua configuração espacial, os ciclos produtivos, suas relações institucionais, e os desafios para a manutenção da produção.

\section{A GÊNESE DO CIRCUITO ESPACIAL DE PRODUÇÃO DE EMBARCAÇÕES NA BAÍA DE GUANABARA: A FORMAÇÃO DE UM AGLOMERADO DE ESTALEIROS}

O Brasil apresenta um extenso litoral, densamente povoado. Essa ocupação litorânea tem origem no processo de colonização realizado por Portugal - potência marítima dos séculos XV e XVI que estabeleceu uma estrutura de povoamento do litoral para o interior. A presença de cidades costeiras fez com que surgissem estabelecimentos voltados para a confecção de embarcações já nesse período, com a formação de pequenos estaleiros artesanais, que construíam canoas e barcos para atenderem às demandas do transporte de cabotagem regional e para a pesca.

A fabricação de embarcações de maior porte começou a ser realizada com a fundação dos Arsenais de Marinha, e ganhou ainda mais força com a vinda da corte portuguesa para o Brasil em 1808. Nesse período, também temos o surgimento de estaleiros particulares, como o Ponta da Areia, atual estaleiro Mauá, que prestava serviços ao Arsenal. Todos esses empreendimentos se instalaram na Baía de Guanabara, nos municípios do Rio de Janeiro - então capital federal - e de Niterói. No Segundo Reinado e na Primeira República outros estaleiros surgiram na região, o que começou a estruturar uma concentração naval ao longo dessa Baía (OLIVEIRA, 2005).

Ao longo de grande parte do século XX, o Estado se fortalece e ganha destaque como impulsionador da ampliação da frota nacional de navios mercantes. Com o surgimento de siderúrgicas nacionais, capazes de fornecer aço para os estaleiros, a perspectiva de consolidar uma indústria naval parecia estratégica para uma circulação de mercadorias mais eficiente no país. Para incrementar o projeto desenvolvimentista dos governos da época, incentivou-se a construção de navios em solo nacional (MOLLO e FONSECA, 2013).

Deste modo, o primeiro grande projeto para uma indústria naval brasileira foi feito no governo de Juscelino Kubitschek, no contexto do Plano de Metas. Esse projeto mesclava uma política protecionista com a atração de capital estrangeiro. A ideia era que a presença de empresas já estabilizadas poderia acabar formando um parque industrial de fornecedores e ainda transferir tecnologia para o país (GOULARTI FILHO, 2013). Verifica-se, portanto, que não havia um investimento direto na indústria nacional, mas sim a possibilidade de adquirir novas metodologias por meio da associação ou do contato com empresas vindas de fora. Deste modo, companhias que mostrassem interesse em se instalar no Brasil, desde que cumprissem com exigências de 
nacionalização, estariam aptas a receber incentivos. Assim, além de reaparelhar estaleiros nacionais já existentes, o Estado garantiu um cenário atrativo para a instalação de dois estaleiros estrangeiros de grande porte no Rio de Janeiro: o Ishikawajima, de origem japonesa, e o Verolme, de origem holandesa.

Havia interesse de que a presença de grandes empresas desencadeasse o surgimento de mais empreendimentos do setor. Valendo-nos da análise de Kon (1994), baseada nas ideias de François Perroux, pode-se afirmar que o interesse em atrair estaleiros estrangeiros veio do caráter motriz que eles apresentariam. Em outras palavras, a produção do estaleiro conseguiria acarretar o aumento do volume de produção de várias outras indústrias ditas "movidas". Deste modo, o Estado incentivava a instalação de empresas centrando-se na máxima de que "a indústria atrai a indústria" (GEORGE, 1973, p.73, grifo do autor); ou seja, a presença de um grande estaleiro estimularia, por um lado, o aumento nos estabelecimentos de navipeças e, por outro, a presença de serviços essenciais para a manutenção de embarcações.

No contexto desse programa governamental, houve a inauguração de diversos estaleiros em Niterói, como o Aliança, o Equipemar e o Renave-Enavi, e a expansão da área de interesse da indústria naval para o município vizinho, São Gonçalo, com a inauguração do estaleiro São Miguel. Havia, portanto, um reforço da Baía de Guanabara como a área central da indústria naval brasileira, pela condição natural de costa abrigada e pela proximidade com uma área de centralidade política e econômica do país.

A maior estruturação de fornecedores e de estaleiros, somada à maior interligação do Brasil com uma lógica global nos indica a conformação de um circuito espacial de produção de embarcações, que, segundo Milton Santos (2012, p.56) compreende as "diversas etapas pelas quais passaria um produto, desde o começo do processo de produção até chegar ao consumo final". A centralidade desse circuito é dada pelos estaleiros, que trabalham, sob encomenda, na montagem ou no reparo de embarcações. Os estaleiros, por sua vez, recebem partes e peças de empresas ligadas a diversos ramos, como, o siderúrgico, o elétrico e o mecânico.

No cenário brasileiro, $\mathrm{o}$ aço e as peças mais simples eram provenientes de fornecedores nacionais. $\mathrm{O}$ motor e outras partes com mais tecnologia vinham de outras partes do mundo. O consumo final cabia aos armadores, que são as empresas, geralmente nacionais, que compram projetos de engenharia naval de grandes escritórios e encomendam a construção das embarcações (SENTURK, 2011). Niterói e São Gonçalo, portanto, se ligavam à cidades de outras partes do Brasil e do mundo, por meio do recebimento de aço e de peças, mas comandavam boa parte da produção das embarcações e do consumo final, já que importantes estaleiros, empresas de navipeças e os armadores estavam localizados nesses municípios.

Enquanto o conceito de circuito espacial de produção possibilita abarcar a dissociação geográfica entre as etapas da produção, existe, ao mesmo tempo, a necessidade de unificá-las. O controle dos movimentos que essa divisão do trabalho produz é realizado, sobretudo, via fluxos imateriais, mediante mensagens, capitais, informações e ordens, que formam círculos de cooperação (SANTOS e SILVEIRA, 2011). Assim, nesse contexto de consolidação do circuito naval, destacamos a criação e renovação de órgãos como o Grupo Executivo da Indústria da Construção Naval (GEICON) e o Fundo da Marinha Mercante, que incrementaram os fluxos informacionais, de ordens e de capitais para o setor no Brasil.

Outra importante medida para a solidificação dos círculos foi a criação de cursos universitários de engenharia naval na Universidade de São Paulo (USP) e na Universidade Federal do Rio de Janeiro (UFRJ), além da criação de uma escola para aprendizes e supervisores no Serviço Nacional de Aprendizagem Industrial (SENAI) em Niterói. A concepção desses cursos permitiu a formação de mão de obra nacional, além de facilitar a troca de conhecimento entre os profissionais.

O circuito espacial de produção de embarcações e os círculos de cooperação permitem, portanto, 
analisar a conformação de uma multiescalaridade geográfica ligada à produção dos navios (Figura 1) (SOUZA, 2013). Em uma escala regional tínhamos a presença de estaleiros e instituições, que respondiam às políticas industriais nacionais. E, por outro lado, os estaleiros e fornecedores se ligavam a uma escala mundial por meio do recebimento de peças e projetos de engenharia.

Por conta da maior concentração geográfica de empresas, fornecedores, prestadores de serviços e instituições, podemos considerar que se formou um cluster naval na região leste da Baía de Guanabara, que compreende Niterói e São Gonçalo (PORTER, 2000). Com essa arquitetura, começou a haver potencial para mais relações de cooperação, com fluxo de informações e intercâmbios em uma escala local e regional. E, consequentemente, a produtividade dos estaleiros passou a ser facilitada pela presença de um aglomerado produtivo e institucional.

Figura 1. Relações escalares do circuito produtivo naval (com ênfase no Rio de Janeiro)

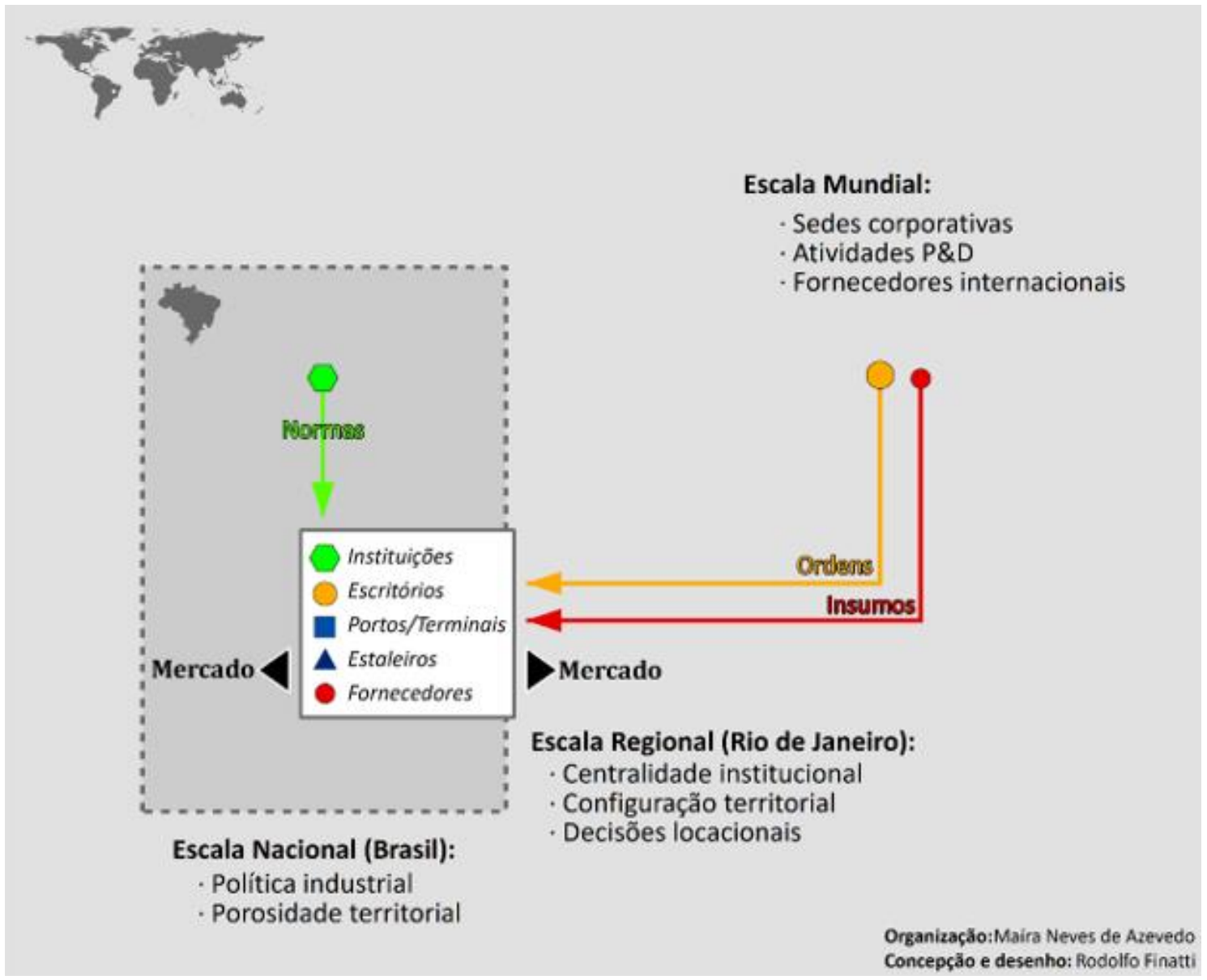

Fonte: Azevedo (2018)

Com o setor já mais consolidado, ao longo dos anos 1960, por meio dos Planos de Construção Naval instituídos no contexto da Ditadura Militar, recomendavam a nacionalização da maior quantidade possível de equipamentos. Esta fase pode ser considerada como a época áurea da indústria naval, em que alguns estaleiros fluminenses chegaram a ter mais de seis mil empregados trabalhando initerruptamente nas mais diversas frentes de produção, construção e reparo (OLIVEIRA, 2005). O estaleiro Mauá se projetou internacionalmente, com a construção de embarcações para Alemanha, Escócia, Grécia, Estados Unidos e Chile. Nesse período, cargueiros, graneleiros, navios frigoríficos e 
superpetroleiros eram os principais tipos de embarcações construídas pelos estaleiros de Niterói e São Gonçalo. Destacamos também a construção da primeira plataforma encomendada pela Petrobras no estaleiro Mauá (OLIVEIRA, 2005).

Nos anos 1970, foram lançados dois planos navais, que previam o financiamento de 74 navios para o aumento da frota das companhias estatais Fronape, Docenave e Lloyd Brasileiro. Apesar de vultosos estímulos, ocorreram muitos atrasos na construção dos navios - com o retardo de até três anos - o que fez com que o custo ultrapassasse o orçamento inicial e fez com que os armadores não tivessem mais condições de contratar novos projetos. Por conta dessa grande encomenda, alguns analistas chegaram a afirmar, à época, que o Brasil teria sido o segundo maior construtor naval do mundo, atrás apenas do Japão. Esta afirmação, todavia, apenas teria se consolidado se todos os navios presentes no plano fossem efetivamente construídos (BARAT, CAMPOS NETO e PAULA, 2014).

Após três décadas de relativo crescimento econômico, a década de 1980 se inicia com sinais de esgotamento no padrão de crescimento. A falta de uma política renovada para a marinha e para os estaleiros acabou instaurando uma profunda crise em todo o circuito produtivo das embarcações, que trouxe dificuldades de liberação de recursos financeiros e atraso nas encomendas. Com isso, os estaleiros passaram a operar em capacidade ociosa, sinalizando o fechamento do ciclo produtivo naval iniciado nos anos 1950 .

A partir dos anos 1990, observamos, no Brasil e no mundo, alterações políticas e econômicas caracterizadas por políticas de privatizações e abertura econômica. Esse discurso foi o tom do governo Collor, que pôs em xeque o projeto desenvolvimentista até então em vigor. Observou-se uma crescente abertura comercial e uma série de privatizações em setores considerados estratégicos, inclusive o naval. O principal marco desse processo foi a promulgação da Lei de Portos, que privatizou e outorgou, através de contratos e arrendamentos, estruturas que, até então, eram operadas apenas pelo Estado. Em 1997 o setor naval sofre um novo golpe, com a permissão de que embarcações estrangeiras afretadas por armadores nacionais atuassem na cabotagem. Isso fez com que houvesse um grande declínio de embarcações de bandeira nacional atuando na costa (GOULARTI FILHO, 2010).

A indiferença quanto à nacionalidade dos navios agravou ainda mais a situação do circuito naval brasileiro. A demanda por construção de embarcações diminuiu, e, com menos dinheiro e somada à dificuldade em seguir as tendências mundiais do setor, quase todos os estaleiros e empresas de navipeças acabaram falindo. Marca esse período a extinção da Lloyd Brasileiro, com o fechamento de seu estaleiro em Niterói. Essa crise foi especialmente drástica neste município e em São Gonçalo, cujas unidades empregavam, aproximadamente, metade dos trabalhadores do ramo no Brasil (FIRJAN, 2016).

Em oposição à situação dramática que o Brasil vivia, alguns países asiáticos se consolidavam como as grandes potências do setor. Japão e Coreia, por exemplo, conseguiram padronizar os navios produzidos, o que reduziu o custo e o tempo de produção. Aos poucos, para alguns armadores, passou a ser mais vantajoso encomendar um navio do outro lado do mundo do que encomendar nos poucos estaleiros nacionais que continuavam existindo, com tecnologia já defasada.

Assim, o único nicho de mercado no Brasil passou a ser os navios feitos sob encomenda (tailor made), envolvendo projetos especiais, com a adaptação das necessidades dos clientes (GOULARTI FILHO, 2010). Com base nesse nicho, a retomada de um novo ciclo da indústria naval só ocorreu nos anos 2000, quando a Petrobras voltaria a ganhar força como cliente, dentro de um novo contexto específico na extração de petróleo offshore, relacionada, principalmente, à descoberta da camada pré-sal. Nesse período, observa-se os primeiros sinais de retomada dos estímulos do Governo Federal para o setor, por meio do lançamento de programas para as atividades ligadas ao circuito espacial de produção de embarcações.

Niterói e São Gonçalo apareceram como pontos estratégicos para receber parte da demanda da Petrobras, devido, dentre outras coisas, à relativa proximidade de Campos e Macaé - principais 
centros de atuação da empresa - e da cidade do Rio de Janeiro - centro de comando e decisão do circuito espacial de petróleo e gás (BINSZTOK, 2012). Podemos afirmar que houve uma reativação temporária do cluster naval existente nos municípios.

\section{A REATIVAÇÃO DO CLUSTER NAVAL DE NITERÓI E SÃO GONÇALO COMO SUPORTE PARA A PRODUÇÃO DE PETRÓLEO}

Após o grande ciclo de produção naval entre os anos 1950 e 1970, nos anos 1980 e 1990 o setor passou por um progressivo declínio, com a falência de empresas (PAULA, 2014). Após esse cenário desolador, em 2012, a UNCTAD (2015) registrou que o Brasil foi o país que realizou o maior volume de construção naval em relação ao tamanho da sua frota. Os dados relacionados ao número de empregados e ao volume de produção de embarcações de 1960 a 2009 demonstram claramente essa retomada (Figura 2). O aumento da demanda foi resultado de uma política estatal de nacionalização do setor como forma de suporte para a exploração de petróleo offshore. Vamos analisar o histórico desse processo.

Figura 2. Evolução do número de empregados e do volume de produção de embarcações no Brasil - 1960 a 2009

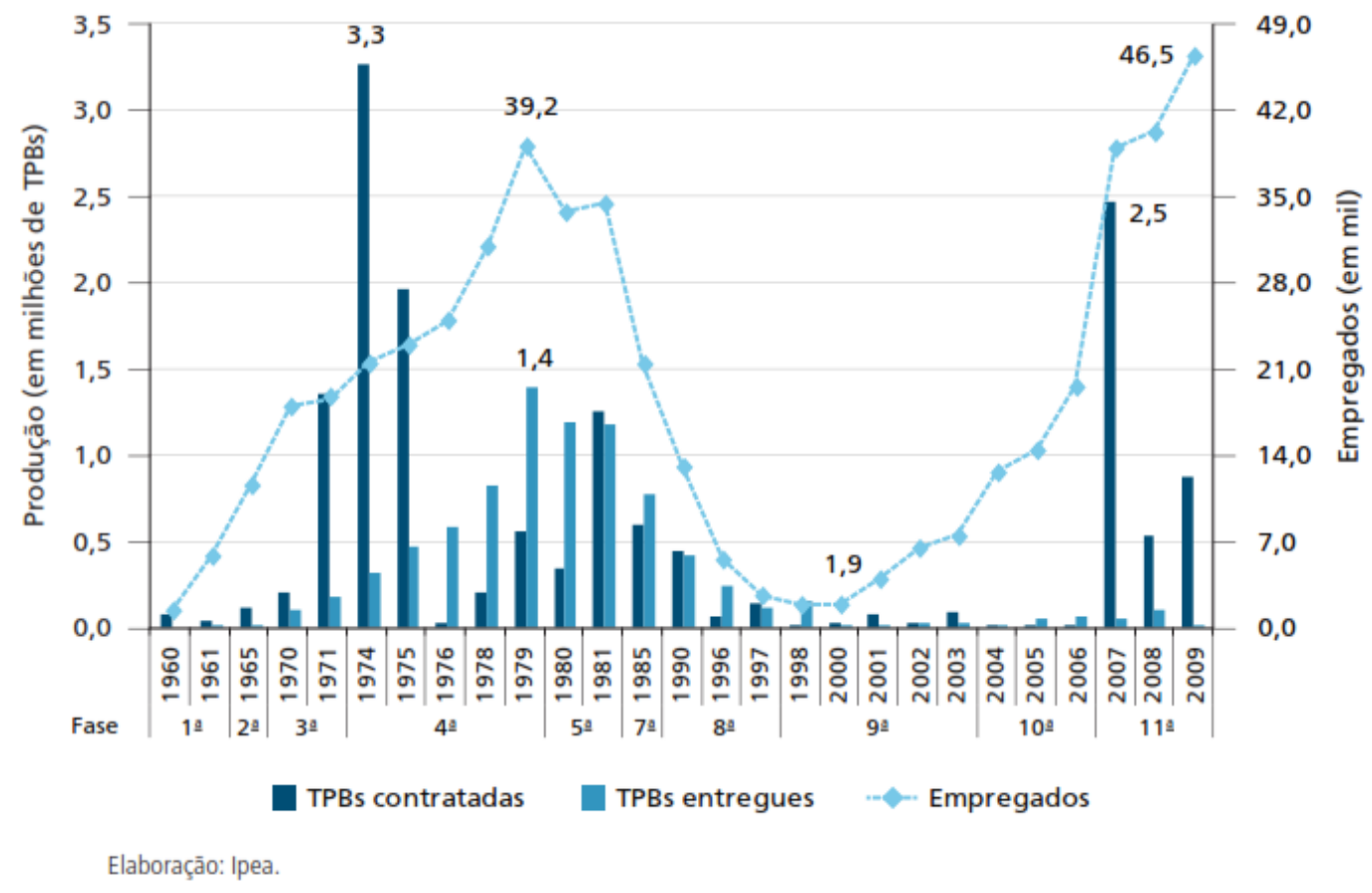

Fonte: Barat, Campos Neto e Paula (2014)

No final dos anos 1990 o governo de Fernando Henrique Cardoso acabou com o monopólio da exploração do petróleo pela Petrobras. Criou-se uma nova arquitetura institucional, que segue os princípios da desestatização e descentralização, com base na criação de Agências Reguladoras para diversos setores. Cabe a essas agências a edição de normas e acordos específicos, conforme as necessidades de cada ramo. É nesse período que é criada a Agência Nacional de Petróleo e Gás (ANP), autarquia e agência reguladora das atividades petrolíferas, a qual, após a promulgação da Lei número 9.478 de 1997 - conhecida como Lei do Petróleo - passou a permitir a pesquisa exploratória deste hidrocarboneto por empresas privadas, inclusive as 
estrangeiras (PIQUET, 2012).

Com os leilões para a exploração de petróleo administrados pela ANP, a Petrobras passou a concorrer no território nacional com transnacionais do setor petrolífero. Esse novo cenário fez com que a empresa começasse a tomar decisões menos "nacionalistas", como a aquisição de plataformas e navios no exterior. Assim, mesmo com a produção de petróleo relativamente alta, no fim da década de 1990, a empresa internacionalizou suas encomendas e perdeu a oportunidade de estimular a indústria naval nacional (GOULARTI FILHO, 2013).

Esse cenário foi se alterando, aos poucos, ao longo dos anos 2000. Com a valorização das commodities, o governo brasileiro viu uma oportunidade para inserir o país na economia global por meio da inclusão do petróleo como objeto crucial para o crescimento econômico do país (PESSANHA, 2017). Deste modo, a Petrobras, a Transpetro e o Estado começaram a ganhar força, novamente, como principais atores para o estímulo ao funcionamento da indústria naval, especialmente por meio da encomenda de navios para a exploração ou apoio à exploração de petróleo.

Ao longo dos anos 2000, o afretamento de um navio petroleiro proveniente de uma grande empresa estrangeira era extremamente caro, em torno de 50 mil dólares por dia (PESSANHA, 2017). De tal modo, com o petróleo valorizado e com o otimismo frente à exploração da camada pré-sal, o governo viu vantagem e achou estratégico lançar programas para estimular a construção de novos estaleiros, novos navios e para o aprimoramento da mão de obra. Assim, foram criados o Programa de Renovação e Expansão da Frota de Embarcações de Apoio Marítimo (Prorefam); o Programa Empresa Brasileira de Navegação (EBN); o Programa de Modernização e Expansão da Frota (Promef) e o Programa de Mobilização da Indústria Nacional de Petróleo e Gás Natural (Prominp). Nesses programas, no geral, a Petrobras apresentava suas demandas e armadores, ou a própria Petrobras, estabeleciam contratos com os estaleiros para a construção de navios.

Além dessas iniciativas, devemos destacar a cláusula de conteúdo local, que exigia um mínimo de $60 \%$ de conteúdo nacional nos equipamentos e serviços utilizados para a exploração de petróleo. Por meio deste dispositivo, assegurou-se que as concessionárias dariam preferência aos fornecedores brasileiros sempre que suas ofertas apresentassem preço, prazo e qualidade equivalentes às de outros fornecedores (DUARTE, 2015).

No bojo desse otimismo da retomada da construção naval, entre 2000 e 2014, dezenove estaleiros de grande e médio porte foram criados. Algumas unidades se instalaram em Estados que não possuíam grandes plantas navais, como Bahia, Espírito Santo e Pernambuco. O Rio de Janeiro, que já possuía um histórico no setor, recebeu cinco unidades, duas delas em Niterói. Os estaleiros remanescentes no município também puderam ser modernizados. Assim, de um lado, tivemos a dispersão da indústria naval pelo território nacional e, de outro, ocorreu um reforço da concentração e o estabelecimento de novas dinâmicas no cluster da Baía de Guanabara (Figura 3).

Mesmo com a possibilidade de construção de navios em estaleiros modernos, como o Atlântico Sul, em Pernambuco, alguns armadores deram preferência para os estaleiros de Niterói e São Gonçalo, o que fez com que pelo menos vinte e oito novas embarcações de médio e grande porte fossem construídas nos municípios entre 2005 e 2015. Dentre as justificativas apresentadas para essa escolha, indicou-se a proximidade com a área de extração de petróleo; com as instituições do setor (como a Petrobras, a ANP, o Sinaval, a Abenav, etc.); com o porto do Rio de Janeiro, de onde podiam receber peças; e pela presença de mão de obra mais qualificada e mais experiente, remanescente do antigo ciclo naval, ou proveniente das universidades do entorno. 
Figura 3. Mapa da distribuição de estaleiros de médio e grande porte por localização e quantidade - 2016

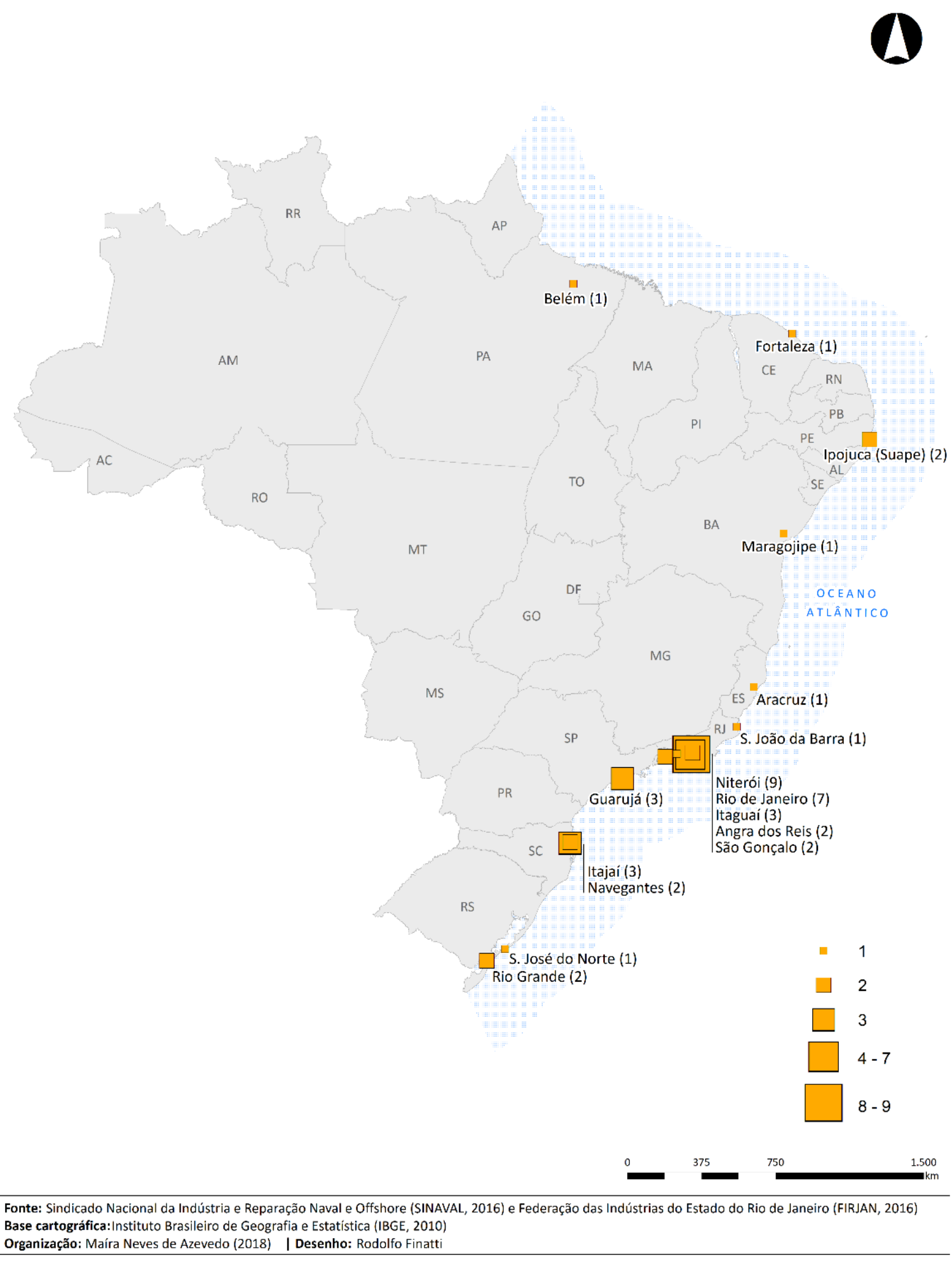

Fonte: Azevedo (2018) 
Deste modo, apesar das oscilações produtivas e da desconcentração de estaleiros pelo território nacional, o Rio de Janeiro, e, em especial, o Centro da capital fluminense, abrigava ainda as principais instituições que animavam o circuito, criando uma densidade institucional (AMIN e THRIFT, 1994). Devemos, portanto, compreender o desempenho das empresas não só por sua própria dinâmica, mas também pelo seu entorno, que compreende o circuito produtivo e os círculos institucionais (FIGURA 4). O cluster permitia a interação com diversas lógicas: a institucional e de gerência, altamente concentrada no Centro do Rio de Janeiro; a concentração de estaleiros em partes do Rio de Janeiro e com destaque para Niterói e São Gonçalo; e os fornecedores, que se encontram mais dispersos. Portanto, para compreendermos a concentração industrial na porção leste da Baía de Guanabara devemos levar em conta a dinâmica de toda a metrópole.

Figura 4. Mapa do cluster naval de Niterói e São Gonçalo: estaleiros, fornecedores e instituições

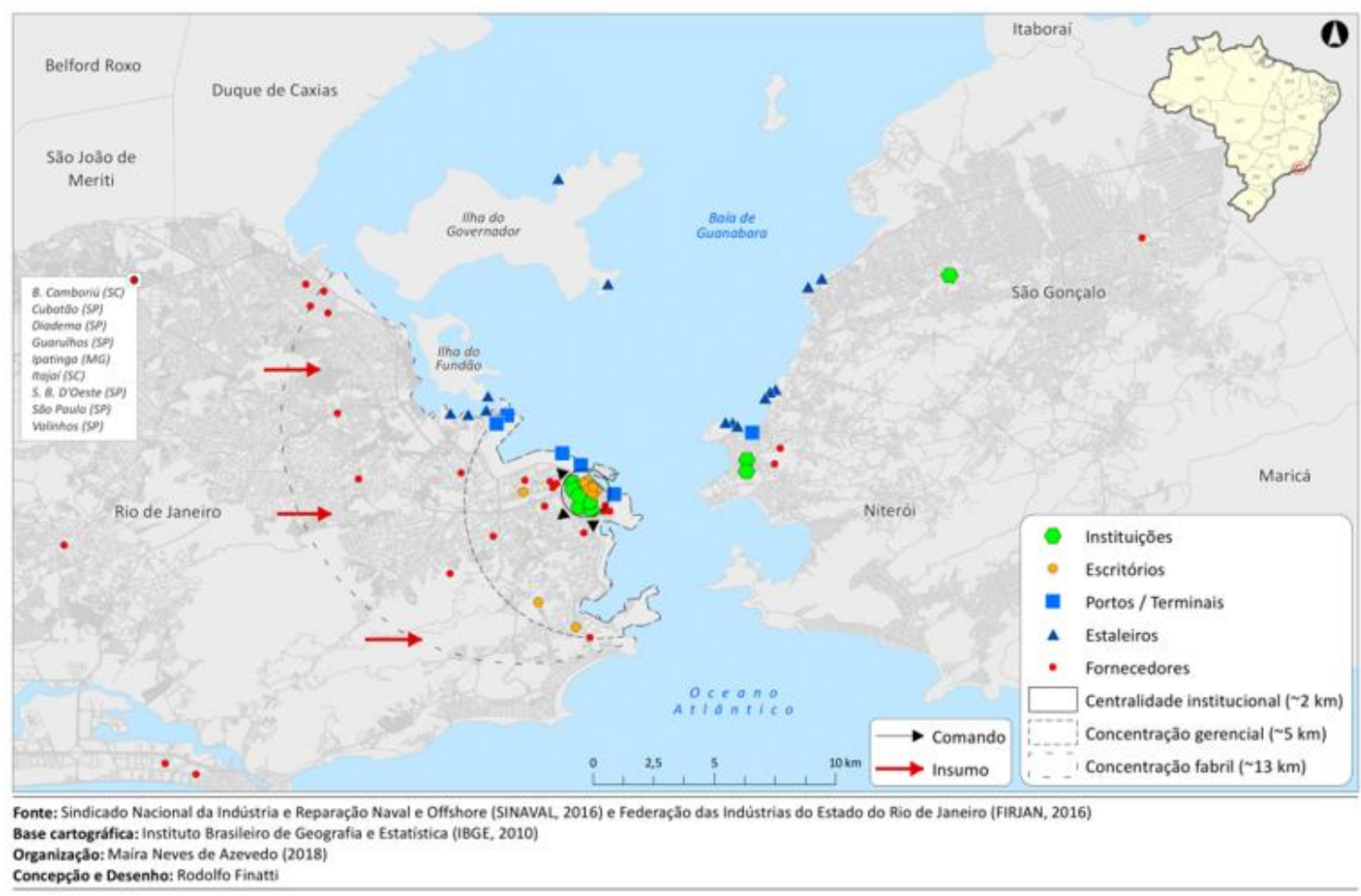

Fonte: Azevedo (2018)

As exigências estabelecidas tanto pelas normas impostas nos contratos empresariais, quanto pelas normas estatais, não condicionaram somente a dinâmica do circuito do petróleo, mas também dos demais agentes e circuitos que as petroleiras estabeleciam vínculos, como o ramo naval. Isso pois, além dos sistemas técnicos sofisticados necessários para a exploração de petróleo, há uma gama de serviços e equipamentos encomendados a outras empresas que são utilizados nas atividades operacionais, de apoio e administrativas. A quantidade de serviços exigidos para a exploração de petróleo faz com que as companhias petroleiras construam uma série de círculos de cooperação, com base em uma rede de empresas prestadoras de serviços e fornecedoras de equipamentos, bem como com universidades e instituições de pesquisa (CAMPOS NETO, 2014).

Além dos estímulos do governo federal, os agentes políticos e econômicos de Niterói e São Gonçalo, também foram chamados a fornecer incentivos por meio da criação de normas que 
contribuíam para a ampliação e consolidação das atividades ligadas à exploração de petróleo e, consequentemente, ao circuito espacial de produção de embarcações. Destaca-se a presença de uma cláusula no Plano Diretor de Niterói (Lei municipal 1.157 de 27 de dezembro de 1992) que indica o compromisso de otimização da indústria naval do município junto ao governo federal. A partir de 2006 o município passou, por exemplo, a garantir redução na alíquota do Imposto sobre Serviços (ISS). São Gonçalo, por sua vez, instaurou por meio da lei municipal 149 de 8 de julho de 2008 o Polo Mecânico Naval do Gradim e, por meio da lei municipal 285 de 23 de junho de 2010 estabeleceu-se também a redução da alíquota de ISS às empresas que se instalassem no município desde que utilizassem $70 \%$ de mão de obra gonçalense.

O aumento da demanda por navios gerou maior complexidade nos círculos de cooperação do circuito espacial de produção de embarcações, já que além do governo federal, as organizações setoriais se reativaram e ganharam corpo para atender aos interesses corporativos. Nesse sentido, houve um maior adensamento de informações, que permitiram ganhos de competitividade em um cenário de competição internacional cada vez mais dominado pelos produtores asiáticos.

Ao longo desse período de reativação do setor, coexistiram em Niterói e São Gonçalo, pequenos estaleiros de capital nacional - cuja área de atuação não ultrapassava o Estado do Rio de Janeiro - e grandes estaleiros - cujo capital procedia de bancos e empreiteiras e, a lógica de atuação se articulava com grandes fornecedores e escritórios de engenharia de fora do país. Segundo dados da Relação Anual de Informações Sociais (RAIS) de 2016, existiam vinte estabelecimentos ligados à construção de embarcações (entre estaleiros e fornecedores), que empregavam milhares de trabalhadores fluminenses. Também por dados da RAIS, estima-se que, em 2014, quase $20 \%$ dos estabelecimentos navais brasileiros estava alocado nos dois municípios.

Como o petróleo é uma mercadoria com um preço muito oscilante, a demanda de embarcações também varia muito ao longo do tempo. Assim, após anos de alta nos preços do petróleo, esse cenário muda em 2015. Junto a isso, uma série de escândalos de corrupção envolvendo a Petrobras deixaram ainda mais delicada a situação do setor petrolífero. Com isso, embarcações começaram a sair do plano de investimentos da empresa e, pela primeira vez em pouco mais de quinze anos, houve mais demissões que contratações na indústria naval de Niterói e São Gonçalo (FIRJAN, 2016)

A vulnerabilidade e dependência da economia global, especialmente pela ligação com o setor petrolífero, fizeram com que a concentração de instituições e de empresas não fossem suficientes para garantir uma produção naval sem oscilações bruscas. Apesar do crescimento econômico alavancado pelo aumento da exploração de petróleo, não vimos um avanço concreto nas bases técnicas nacionais. Em meio a toda essa crise política e institucional, é mister analisarmos as possibilidades de manutenção da produtividade do circuito para que haja continuidade de emprego e renda.

\section{O CLUSTER NAVAL FLUMINENSE, POSSIBILIDADES PARA O DESENVOLVIMENTO TERRITORIAL E DIFICULDADES PARA SE REPOSICIONAR NO SETOR}

As delimitações das unidades da paisagem, por fim, ajudam a identificar quais porções do território apresentam fragilidades ambientais ou potencialidades de uso isso contribui de forma demasiada na gestão do território como forma de pensar em alternativas para o melhor aproveitamento dos recursos naturais.

Desde 2015 existe um cenário pautado, majoritariamente, por pedidos de recuperação judicial 
de estaleiros, demissões e futuro incerto para os trabalhadores navais. Estima-se que, nesse período, o setor tenha perdido cerca de $40 \%$ dos empregos diretos (FIRJAN, 2016). Os dados do número de estabelecimentos e de vínculos empregatícios em Niterói e São Gonçalo escancaram essa queda e demonstram o futuro incerto para os trabalhadores (Figuras 5 e 6 ).

Figura 5. Estabelecimentos de Construção e Reparação de embarcações e estruturas flutuantes em Niterói e São Gonçalo - 2002 a 2016

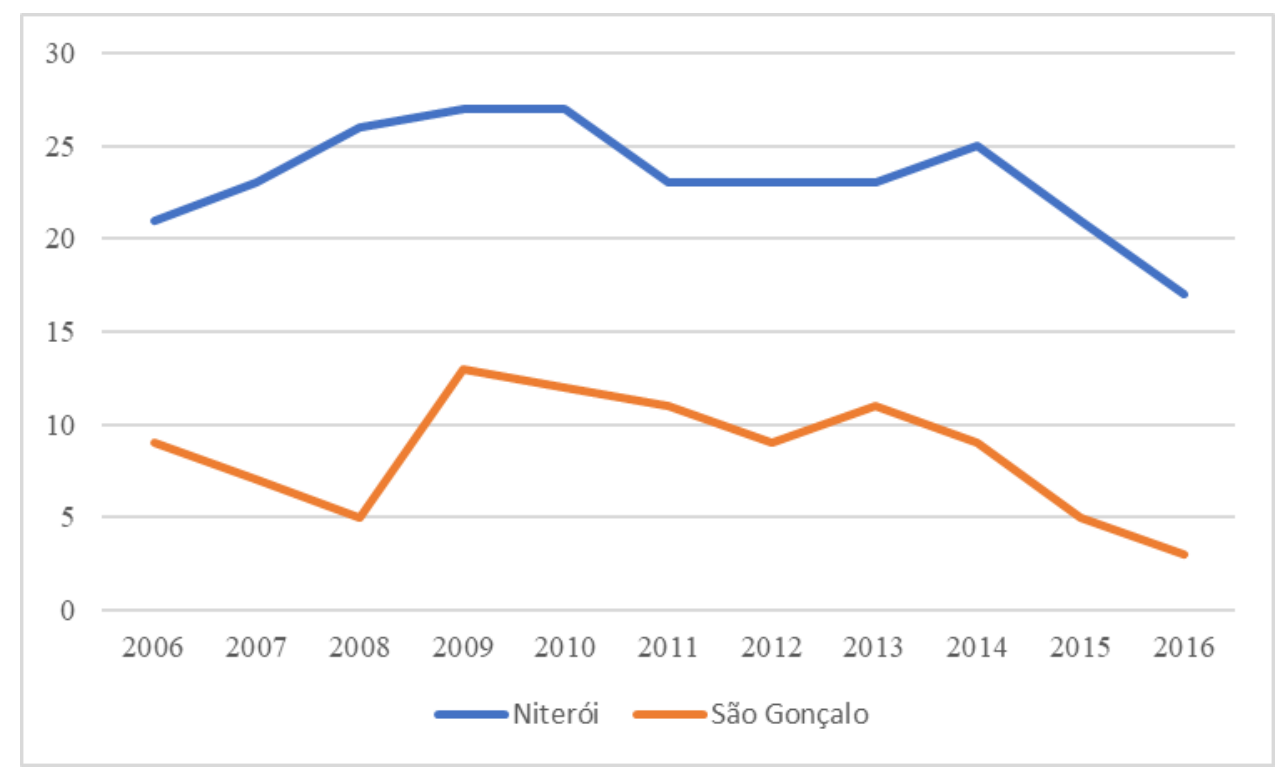

Fonte: RAIS (2002 a 2016)

Figura 6. Vínculos empregatícios de Construção e Reparação de embarcações e estruturas flutuantes em Niterói e São Gonçalo - 2002 a 2016

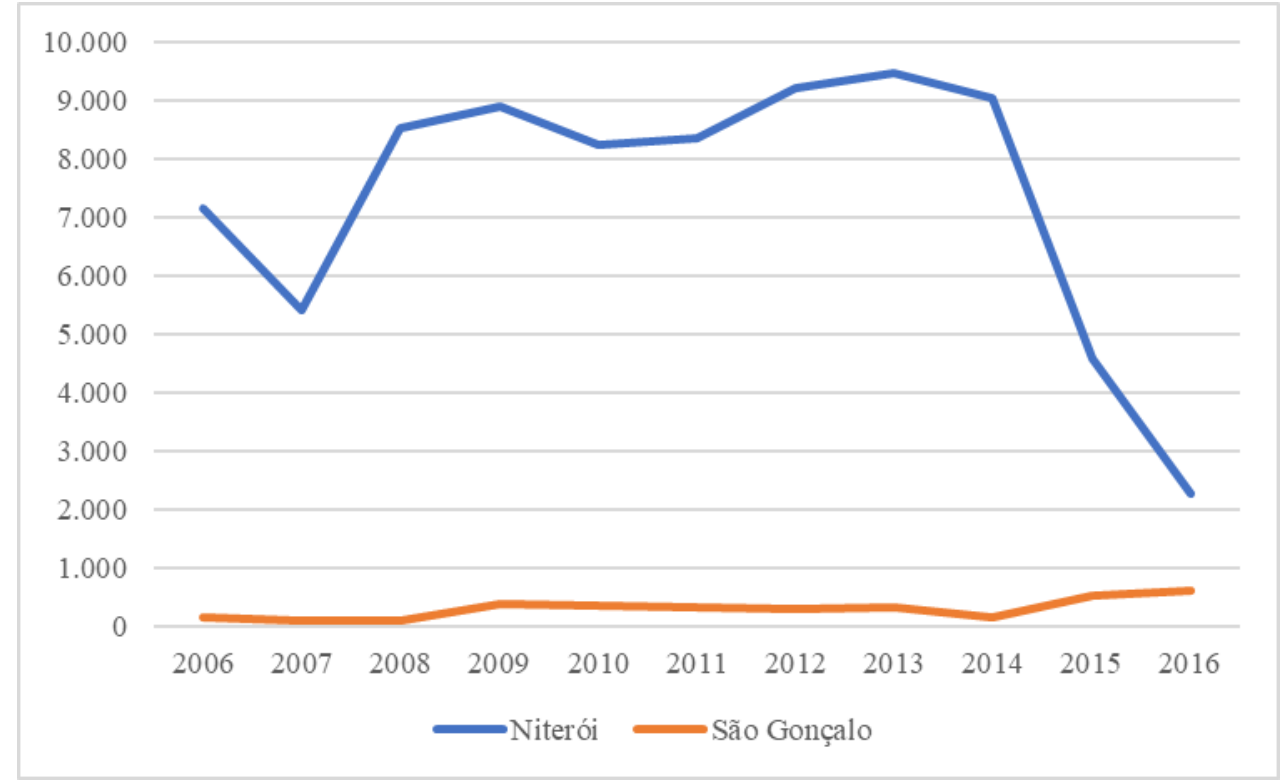

Fonte: RAIS (2002 a 2016) 
Os vultosos investimentos para a produção de navios não foram capazes de sustentar uma indústria naval com tecnologia majoritariamente nacional, seja no âmbito dos projetos de engenharia, seja na constituição de um setor de navipeças mais consolidado (CERQUEIRA JR., 2014). A relação direta com o petróleo não foi capaz de gerar um planejamento a longo prazo, com ênfase em inovação, para que o setor naval não sentisse de forma tão dramática as oscilações no preço desse hidrocarboneto. Em um contexto de grande preponderância dos países asiáticos, constatou-se que as políticas estatais foram capazes de incluir o Brasil apenas de forma periférica na produção mundial de embarcações.

Liderado por uma frente política composta por grandes grupos industriais, empreiteiras e o agronegócio exportador, esse período de retomada da produção pode ser entendido pela tentativa de conciliar aspectos ditos positivos do neoliberalismo - como a estabilidade da moeda, a austeridade fiscal e a busca por competitividade internacional - e, por outro lado, aspectos ditos positivos do antigo desenvolvimentismo - como o compromisso com o crescimento econômico, industrialização e a garantia do papel regulador do Estado. No geral, existia a crença de que o crescimento econômico por meio de políticas públicas e condições especiais para empresas seria a chave para o enfrentamento das desigualdades (SAMPAIO JR., 2012). Apesar de ao longo dos governos Lula termos visto essa tentativa de conciliação dos interesses do capital financeiro, da burguesia interna e da classe trabalhadora organizada, no governo Dilma passou-se por uma conjuntura econômica mundial mais desfavorável, que escancarou os limites dessa política (PESSANHA, 2017). Grandes grupos empresariais, como as empreiteiras, que atuam como investidoras na indústria naval e de petróleo, se rearticularam na tentativa de implodir esse projeto e pressionar a tomada de medidas mais neoliberais. $\mathrm{O}$ gradual desmanche da indústria naval fluminense entra nesse contexto.

Todo esse histórico de abertura e fechamento dos estaleiros ao longo do século XX e nas primeiras décadas do século XXI nos faz perceber que, no caso de Niterói e São Gonçalo, a configuração de forma aglomerada, em um cluster, com a presença de instituições e de companhias, por si só, não sustenta a produção em longo prazo, visto que temos uma produção extremamente cíclica. Assim, apesar dos aspectos positivos trazidos pela proximidade, uma série de fatores contribuíram para essa constante quebra.

Em entrevistas com trabalhadores do setor naval fluminense, apontaram como um importante fator para a ciclicidade, a falta de investimento em uma base de fornecedores para itens altamente tecnológicos no Brasil, como os motores e os sistemas de posicionamento dinâmico. A importação desses itens acaba encarecendo a produção do navio, já que as partes produzidas localmente, como o aço, parafusos, tintas e tubulações são as mais baratas.

Outro fator apontado é a dificuldade de formar um chão de fábrica com anos contínuos de experiência. Apesar de termos engenheiros navais e oficiais de marinha mercante capacitados na Região Metropolitana do Rio de Janeiro, ocorre dificuldade de conseguir mão de obra qualificada, principalmente para soldagem. A oscilação produtiva impede que haja uma formação continuada dos trabalhadores, com acúmulo constante de experiência. Quando a crise se instaura, alguns desses trabalhadores são demitidos e partem para trabalhos em áreas completamente diferentes, que não exigem formações específicas, como motoristas de aplicativos, vendedores ou camelôs. Assim, se porventura a produção voltar, essas pessoas precisariam retomar conhecimentos que já estavam parados e defasados. Alguns engenheiros navais, por sua vez, passam a trabalhar em empresas de consultoria ou no mercado financeiro. Em suma, a oscilação produtiva de todo o circuito das embarcações impede que haja uma formação continuada dos trabalhadores, fazendo com que seja difícil a consolidação da mão de obra como um recurso específico (PECQUEUR, 2005), capaz de garantir singularidade para a produção de Niterói e São Gonçalo.

Ressalta-se ainda que alguns recursos oferecidos pelos municípios, como a localização em uma baía, podem ser transferíveis, ou seja, podem ser encontrados facilmente em outros lugares do 
mundo, até de um jeito mais vantajoso (como a presença de mão de obra ainda mais qualificada, proximidade com fornecedores de ponta, etc.). Isso faz com que o ramo naval fluminense não tenha uma produção tão singular, ancorada ao território. Deste modo, normas, como as cláusulas de conteúdo local, acabaram sendo essenciais para estimular, por meios legais, a produção naval com bases nacionais, já que o contexto internacional do circuito apresenta valores mais competitivos e prazos mais curtos em países como a China, o Japão e a Coreia do Sul.

Com base na análise dos estaleiros de Niterói e São Gonçalo, não consideramos que já tenha existido algum planejamento da indústria naval com ênfase em inovação a longo prazo, e estímulo à continuidade da mão de obra local. Nesse sentido, vemos que no lugar da mobilização dos atores para o advento de uma trajetória produtiva territorializada, as políticas tiveram um aspecto mais setorial, por meio da atração e manutenção de empresas nos municípios pela garantia de uma situação fiscal e tributária favorável (PECQUEUR, 2005).

Alguns teóricos indicam que uma possível alternativa para a geração de singularidades, que auxiliariam uma produção mais estável a longo prazo, seria o fortalecimento de redes de associações, organizações coletivas e instituições políticas e sociais (AMIN e THRIFT, 1994). $\mathrm{O}$ intuito desses dispositivos seria articular e fortalecer os atores, para que, junto do Estado, possam discutir alternativas para uma inserção mais única no setor, com base em inovação. Um exemplo de decisões tomadas nesse sentido ocorreu em Saint Nazaire - cidade localizada na costa atlântica francesa - que se especializou na produção de porta-aviões e cruzeiros transatlânticos após um intenso processo de crise. A presença de Associações e Sindicatos navais na Região Metropolitana do Rio de Janeiro gera potencial para a existência de discussões a longo prazo.

Algumas iniciativas para a retomada de partes do circuito das embarcações já foram ou estão sendo tomadas. Grupos de empresas e estudos da Federação das Indústrias do Estado do Rio de Janeiro (FIRJAN) discutem a possibilidade de especialização do cluster para o reparo naval, já que se trata de uma atividade mais constante que a construção de embarcações. Outros acreditam que o fim da obrigatoriedade da Petrobras na exploração do pré-sal poderia atrair mais clientes para o reparo e para a manutenção (FIRJAN, 2016).

Nesse sentido, a prefeitura de Niterói, vem estimulando que os estaleiros dependam menos da construção de navios e se voltem para atividades como o reparo, certificação de navios e o desmonte, já que empresas como a Gerdau compram o aço para a reutilização em outras atividades. Como primeiro passo desta reestruturação, reduziu-se o ISS do setor de $3 \%$ para $2 \%$. Além disso, criou-se um Conselho de Autoridade Portuária em Niterói, que oficializa o porto; iniciou-se um projeto de dragagem para permitir a circulação de embarcações maiores; e licitouse um guindaste para que seja permitida a realização de novas atividades, como o transbordo de cargas grandes. Com isso, todos os estaleiros do município, por terem locais para atracação de embarcações, viraram Terminais de Uso Privativo, que são instalações privadas em que o responsável possui direito de operar os fluxos que lhe interessa, seja em uso público ou privativo. Essa mudança já permitiu um aumento da arrecadação do município entre em 2018 e 2019 (MOURÃO, 2018).

No ano de 2019 também foi assinado um plano governamental para oficializar o Cluster Tecnológico Naval do Rio de Janeiro, que reuniria todos os estaleiros localizados na Baía de Guanabara, as instituições do setor e as universidades. Esse projeto foi idealizado pela Empresa Gerencial de Projetos Navais e visa reforçar a integração entre o circuito naval aos setores de petróleo e gás, portuário e o pesqueiro. Além da construção e do reparo, o cluster se voltaria para a venda de cartas náuticas, levantamentos hidrográficos, manutenção de embarcações, docagens e perícias.

Ainda não é possível saber se essa medida permitirá que a produção naval fluminense se sustente a longo prazo, com a presença de uma produção mais única e territorializada. Essa 
previsão fica ainda mais delicada com as consequências econômicas trazidas pela pandemia do novo coronavírus ao longo de 2020. Em todo o caso, acredita-se que, embora tenha um viés mais setorial, essa iniciativa pode permitir que os atores locais e regionais se rearticulem, com atuação mútua de empresas, instituições e trabalhadores. Vemos também uma tentativa de menor dependência ao ramo petrolífero, o que pode garantir mais estabilidade para a indústria naval.

A partir de redes institucionais locais, que produzam informações sobre seu meio, pode-se ampliar a coesão da sociedade civil a serviço de um interesse mais coletivo das populações de Niterói e São Gonçalo. Em suma, acredita-se que as relações mais horizontais, com uma solidariedade orgânica (SANTOS e SILVEIRA, 2011), devem ser levadas em conta para que haja continuidade da produção naval, de forma a atender às demandas locais de emprego e renda de maneira mais autônoma, podendo apontar para um futuro socialmente mais promissor.

\section{CONSIDERAÇÕES FINAIS}

Desde a segunda metade do século XX, a produção mundial de navios está altamente polarizada por países asiáticos, que comandam não só os principais estaleiros, como também importantes fornecedores e bases de pesquisa. Países, como o Brasil, ocupam um lugar mais periférico nessa produção, com dependência tecnológica dos países centrais do ramo. Apesar dessas distinções, a indústria naval mundial tem como característica a frequente organização em forma de aglomerados. A necessidade de proximidade de cursos d'água estimula esse processo e gera externalidades positivas, como a concentração geográfica de fornecedores, de trabalhadores, de troca de conhecimentos e um acúmulo de saber-fazer.

A principal concentração de estaleiros no Brasil ocorre no entorno da Baía de Guanabara, em municípios como Niterói e São Gonçalo. Trata-se de um aglomerado antigo, formado pela localização estratégica e pela proximidade com a antiga capital do país em um período que a navegação era um dos principais meios de transporte. Nesse sentido, em um primeiro momento, os estaleiros estavam mais ligados à circulação interna e à pesca. Ao longo do século XX, os tipos de navios fabricados foram mudando, com a produção de embarcações para longo curso, cabotagem e, por último, para a produção de petróleo.

A estruturação de fornecedores, armadores, instituições, universidades e centros de pesquisa nesse entorno nos possibilita dizer que existe um cluster naval ligado a um circuito espacial de produção de embarcações. Nesse circuito, o Estado e suas empresas possuem papel central para a cooperação entre os atores por meios de normas e leis. Conforme apresentamos, em determinados períodos, a indústria naval apareceu como um setor estratégico para a circulação de mercadorias ou como subsídio a outras atividades econômicas, o que fez com que o ramo ganhasse estímulos estatais. Em outros momentos, esse quadro cessou e ocorrem demissões em massa e fechamento de estabelecimentos. Essa dependência estatal faz com que seja um ramo muito cíclico.

O último grande ciclo da indústria naval ocorreu entre os anos 2000 e 2014, quando o aumento no preço das commodities e o otimismo frente à descoberta da camada pré-sal fizeram com que o governo e a Petrobras lançassem uma série de programas que permitiram a construção de diversas embarcações, com a geração de muitos empregos. Após 2015, o contexto político e macroeconômico se altera e ocorre uma nova crise no setor, com muitas demissões e falências. Ensaia-se uma retomada de partes do circuito desde 2019, voltando-o, principalmente, para o reparo de embarcações, mas o futuro econômico é extremamente incerto. Nesse sentido, além de uma política estatal que favoreça uma indústria nacional, acreditamos que seja necessário que os diversos atores locais do cluster de Niterói e São Gonçalo se mobilizem para que haja soluções inovadoras, com pensamentos a longo prazo. 
O estímulo à atuação de grandes indústrias muitas vezes é apresentado como a panaceia para os problemas existentes em municípios localizados na periferia de grandes metrópoles. Contudo, nessas áreas o desemprego de longa duração continua e a população é chamada a financiar indiretamente os estímulos dados às empresas. Por isso, é preciso salientar que o circuito espacial de produção de embarcações, muitas vezes, é comandado por instituições que possuem relações verticais com o território nacional. Assim, assistimos uma drenagem dos recursos locais para o setor privado ao invés de melhorias sociais. Acreditamos, portanto, que o fortalecimento das relações horizontais e a mobilização dos atores locais poderiam transformar a indústria naval dos municípios em um vetor efetivo de desenvolvimento territorial.

\section{AGRADECIMENTOS}

Agradecemos o apoio da Fundação Carlos Chagas Filho de Amparo à Pesquisa do Estado do Rio de Janeiro (FAPERJ) pelo financiamento da pesquisa por meio da Bolsa Mestrado Nota 10, que permitiu a realização desse estudo.

\section{REFERÊNCIAS}

AMIN, A.; THRIFT, N. Living in the global. In: AMIN, A.; THRIFT, N. (eds) Globalization, Institutions and Regional Development in Europe. Londres: Oxford University Press, 1994.

ARROYO, M.M. Território, mercado e estado: uma convergência histórica. GEOgraphia. Niterói, ano 6, n. 12, 2004.

AZEVEDO, M. N. A reestruturação do circuito espacial de produção de embarcações: análise dos estaleiros de Niterói e São Gonçalo (1970-2017). Dissertação de Mestrado (Mestrado em Geografia), Universidade Federal do Rio de Janeiro, Rio de Janeiro, 2018.

BARAT, J.; CAMPOS NETO, C. A. S.; PAULA, J. M. P. Visão Econômica da implantação da indústria naval no Brasil: aprendendo com os erros do passado. In: CAMPOS NETO, C. A. S.; POMPERMAYER, F, M (orgs.). Ressurgimento da Indústria Naval no Brasil: 2000-2013. Brasília: Ipea, 2014.

BINSZTOK, J. A cidade do Rio de Janeiro e a cadeia produtiva de petróleo. In: MONIÉ, F; BINSZTOK, J. (orgs.). Geografia e geopolítica do petróleo. Rio de Janeiro: Muad X, 2012.

CAMPOS NETO, C. A. S. Investimentos e financiamentos na indústria naval brasileira 2000-2013. In: CAMPOS NETO, C. A. S.; POMPERMAYER, F, M (orgs.). Ressurgimento da Indústria Naval no Brasil: 2000-2013. Brasília: Ipea, 2014.

CERQUEIRA JR., M. J. B. Possibilidades de fomento às firmas brasileiras de engenharia de projeto da indústria naval. In: CAMPOS NETO, C. A. S.; POMPERMAYER, F, M (orgs.). Ressurgimento da Indústria Naval no Brasil: 2000-2013. Brasília: Ipea, 2014.

DUARTE, L. Concretude territorial e regulação híbrida: a política de conteúdo local no setor de exploração e produção de petróleo e gás. Anais do XI Encontro Nacional da ANPEGE, p.8554-8565, 2015.

EGLER, C. A. G.; MATTOS, M. M. C. L. Multinacionais do setor petrolífero, geoeconomia e integração regional na América do Sul. In: MONIÉ, F; BINSZTOK, J. (orgs.). Geografia e geopolítica do petróleo. Rio de Janeiro: Muad X, 2012.

FIRJAN. Panorama naval no Rio de Janeiro - 2016. Rio de Janeiro: FIRJAN, 2016.

GEORGE, P. Geografia Econômica. Rio de Janeiro: Fundo de cultura, 1973.

GOULARTI FILHO, A. A trajetória da Marinha Mercante Brasileira: administração, regime jurídico e planejamento. Pesquisa \& Debate, São Paulo, v. 21, n. 2(38) p. 247-278, 2010

Empresas estatais e a consolidação da indústria de construção naval brasileira. H-industri@, Buenos Aires, n. 12, 2013. 
KON, A. Economia Industrial. São Paulo: Nobel, 1994.

MOLLO, M. L. R.; FONSECA, P. C. D. Desenvolvimentismo e novo-desenvolvimentismo: raízes teóricas e precisões conceituais. Brazilian Journal of Political Economy - Revista de Economia Política, São Paulo, v. 33, n. 2, p.222-239, 2013.

MONIÉ, F. As cidades portuárias diante do imperativo de fluidez. Território, circulação e reestruturação das hinterlândias dos portos. In: ARROYO, M. M.; CRUZ, R. C. Território e Circulação: a dinâmica contraditória da globalização. São Paulo: Annablume, 2015.

MONIÉ F.; VIDAL S. M. S. C. Cidades, portos e cidades portuárias na era da integração produtiva. Revista de Administração Pública, Rio de Janeiro, v.40, n.6, p. 975-996, 2006.

MOURÃO, G. Na contramão da crise, receita da indústria naval de Niterói cresce $47 \%$ em um ano. O Globo, Rio de Janeiro, 25 ago. 2018.

OLIVEIRA, R. O. Ponta d'Areia: o berço da Construção Naval. São Paulo: Quiron, 2005.

PAULA, J. M. P. Perfil de capacitação e acesso às políticas de inovação das empresas de navipeças. In: CAMPOS NETO, C. A. S.; POMPERMAYER, F, M (orgs.). Ressurgimento da Indústria Naval no Brasil: 2000-2013. Brasília: Ipea, 2014.

PECQUEUR, B. O desenvolvimento territorial: uma nova abordagem dos processos de desenvolvimento para as economias do sul. Raízes. Campina Grande, v. 24, n. 1, 2005.

PESSANHA, R. M. A relação transescalar e multidimensional "Petróleo-Porto" como produtora de novas Territorialidades. Tese de doutorado (Doutorado em Políticas Públicas e Formação Humana), Universidade do Estado do Rio de Janeiro, Rio de Janeiro, 2017.

PIQUET, R. Petróleo e desenvolvimento regional no Brasil. In: MONIÉ, F; BINSZTOK, J. (orgs.). Geografia e geopolítica do petróleo. Rio de Janeiro: Muad X, 2012.

PORTER, M. E. Locations, Clusters and Company Strategy. In.: CLARCK, G.; FELDMAN, M. P.; GERTLER, M. The Oxford Handbook of Economic Geography. New York: Oxford University Press Inc., 2000.

RELAÇÃO ANUAL DE INFORMAÇÕES SOCIAIS (RAIS). Ministério do Trabalho e Emprego Programa de disseminação de estatísticas do trabalho (PDET). 2002, 2003, 2004, 2005, 2006, 2007, 2008, 2009, 2010, 2011, 2012, 2013, 2014, 2015, 2016.

SAMPAIO JR. P. A. Desenvolvimentismo e neodesenvolvimentismo: tragédia e farsa. Serviço Social \& Sociedade, São Paulo, n. 112, p. 672-688, out./dez,2012.

SANTOS, M. A Natureza do Espaço: Técnica e Tempo, Razão e Emoção. 4. ed. 4. reimpr. São Paulo: Edusp, 2008.

Metamorfoses do Espaço Habitado: Fundamentos Teóricos e Metodológicos de Geografia. 6. ed. 1. reimpr. São Paulo: Edusp, 2012.

SANTOS, M.; SILVEIRA, M. L. O Brasil: território e sociedade no início do século XXI. 15. ed. Rio de Janeiro: Record, 2011.

SENTURK, O. U. The interaction between the ship repair, ship conversion and shipbuilding industries. OECD Journal: General papers, V.3, p.7-36, 2011.

SOUZA, M. L. Os Conceitos Fundamentais da Pesquisa Sócio-espacial. 1 ed. Rio de Janeiro: Bertrand Brasil, 2013.

SINAVAL. Mapa dos estaleiros do Brasil. Rio de Janeiro: Sinaval, 2016.

UNCTAD. Informe sobre el transporte marítimo. Nova Iorque: ONU 2015. 